\title{
Application of a Conceptual Hydrological Model to Identify the Impacts of Green Roof Substrate Ageing on Detention Performance
}

\author{
S. De-Ville, V Stovin \\ Department f Civil \& Structural Engineering, Faculty of Engineering, University of Sheffield.
}

\begin{abstract}
The substrate within a green roof is subject to numerous natural processes throughout its intended design life. As such there is a need to identify the impacts these processes have on substrate hydrological performance over time. Presented is a conceptual hydrological green roof model that utilises non-linear reservoir routing techniques to parameterise detention processes into scale, $k$ and exponent, $n$. The value of $n$ can be fixed as it largely influenced by the roofs construction (roof slope, drainage length, etc.), thus reducing the model to a single parameter, $k$. Using observed rainfall/runoff data from test beds at The University of Sheffield values of $k$ were identified for a series of 25 events over a period of 4 years. A rise in the mean value of $k$ was observed for each year of the study, indicating a reduction in detention performance. A design storm exercise allows for the changes in detention performance to be quantified in commonly reported detention metrics.
\end{abstract}

\section{Keywords Green Roof; Hydrology; Modelling; Substrate Ageing; Detention}

\section{INTRODUCTION}

Green roof substrates are subject to a number of processes that are likely to result in changes to their hydrological performance as they age. Key processes include root system development, organic matter turnover, substrate consolidation and chemical interactions with rainwaters. There is currently little understanding surrounding the magnitude of these changes and whether performance over time should be considered at the design stage.

A generic conceptual hydrological green roof model was first proposed by Kasmin et al. [1] and has since been developed and validated by Stovin et al. [2]. This model includes both retention and detention processes to accurately indicate green roof runoff for rainfall input data. This study focuses on detention performance only. The detention effects are modelled using a simple reservoir routing approach which requires only two parameters, $k$ and $n$. The construction of the green roof (slope, drainage length, etc.) has been seen to be the main factor in determining $n$, whilst $k$ is influenced by the substrate and vegetation [3].

Existing research has identified that an increase in either substrate depth or organic matter content leads to a reduction in the value of $k$ [4], and hence an increase in green roof detention performance. Levels of organic matter within a green roof have been observed to change with time, and both increases [5, 6] and decreases [7] have been identified. Reduced levels of organic matter are caused by decomposition, which then leads to substrate shrinkage [8], resulting in a compounded elevation in the value of $k$.

Using 4 year rainfall/runoff data series collected from green roof test beds (located on the roof of the Turner Museum of Glass, Hadfield Building, The University of Sheffield) values of $k$ will be determined for each year of the study. These values will be used to determine the changes in detention performance seen from year to year.

\section{MATERIALS AND METHODS}

\subsection{INPUT DATA}

A series of 25 events was isolated from a record of over 300 , the selected events produced valid runoff profiles and exhibited more than $75 \%$ runoff. The majority of the 25 events contain an element of retention. This needs to be removed so a detention only event can be analysed. This is achieved by removing the initial losses (retained rainfall) from the start of the rainfall record.

\subsection{The Generic Green Roof Model}

Detention processes are modelled using reservoir routing techniques:

$h_{t}=h_{t-1}+$ Qin $_{t} . \Delta t-Q o u t_{t} . \Delta t \quad$ Qout $_{t}=k h_{t-1}^{n}$ (1)

Where Qin and Qout are the flow rates into and out of the substrate layer, measured in $\mathrm{mm} / \mathrm{min}$. $h$ is the depth of water temporarily stored within the substrate, in $\mathrm{mm}$. $\Delta t$ is the discretization time step. $k$ and $n$ are the reservoir routing parameters where $k$ has the units $\mathrm{mm}^{(1-n)} / \mathrm{min}$ and $n$ is dimensionless.

\subsection{Data ANalysis}

For each of the 25 events a fixed value of $n=2$ was used [1, 2], $k$ was then optimised using a least squares regression technique. The 25 events were then divided into groups by their year of study. The mean $k$ value from each group was then determined and any year to year trends identified.

\subsection{Design StORM Detention}

Whilst long term monitoring has allowed for the determination of any trends in $k$ over time, the inherent variability of rainfall and other climate conditions makes finding an identical event across years for direct comparison almost impossible. Therefore it is useful to determine the hydrological response to a design storm (M100 45, 75\% summer storm for Sheffield) from the differing values of $k$. 

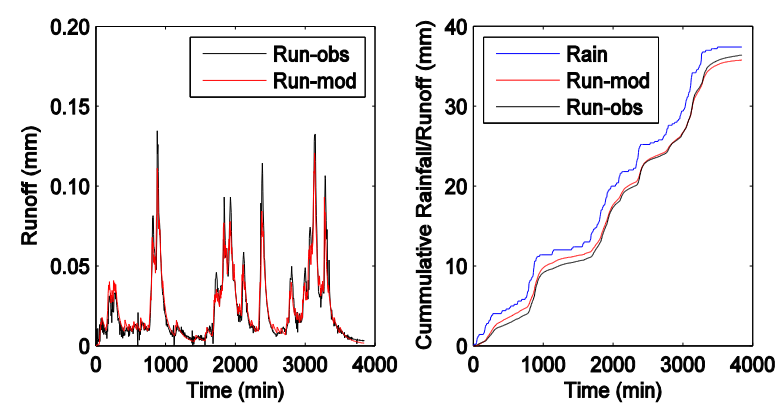

Figure 1. Observed and modelled runoff for Event 7.

\section{RESULTS}

The generic model predicted runoff with an acceptable level of accuracy, some $56 \%$ of events had an $\mathrm{R}^{2}$ greater than 0.9 . An example of a strong model fit can be seen in Fig. 1 for event 7. Overall values of $k$ ranged from 0.003 to 0.065 ; such results are similar in magnitude to other published outcomes $[1,4]$. The mean values of $k$ for each year of study showed a year-on-year increase. By year 4 the mean value of $k$ had increased by $74 \%$ from 0.0098 to 0.0170 (Fig. 2). An independent samples Kruskal-Wallis test found that there was no significant difference in the distribution of $k$ across the years of the study ( $P=0.0935,0.05$ Significance level).

Table 1 details the differences in common detention parameters as a result of the increase in $k$ for the 45 minute design storm. Over the 4 years peak runoff has increased by $20 \%$ and peak attenuation has decreased by $13 \%$. Peak delay has not changed, however centroid delay, which is a more robust overall measure of delay has decreased by $30 \%$.

\section{Discussion}

An increase in the value of $k$ suggests that the substrate may have undergone a degree of organic matter decomposition. The test bed is covered with a layer of sedum vegetation which has a shallow fibrous root system. This prevents the introduction of organic matter to deeper levels within the substrate and, as such, the original organic matter in these regions is likely to decompose. The increase in $k$ may also be compounded by a reduction in substrate depth associated with shrinkage as a result of organic matter decomposition or natural consolidation. The slowing rate of increase in $k$ from years 2 to 4 could suggest a stabilisation of organic matter content at a lower percentage than the virgin substrate. This fits theories that suggest a green roof substrate will stabilise with age [9].

Rainfall simulations conducted at two different rainfall intensities found that $k$ decreased with increased intensity [4], however no significant correlation was seen in the 25 event dataset This indicates that the changes in $k$ over time are not due to differing distributions of rainfall events between years.

\section{CONCLUSIONS}

It was found that $k$ saw a year-on-year increase resulting in a decrease in detention performance. The exact processes

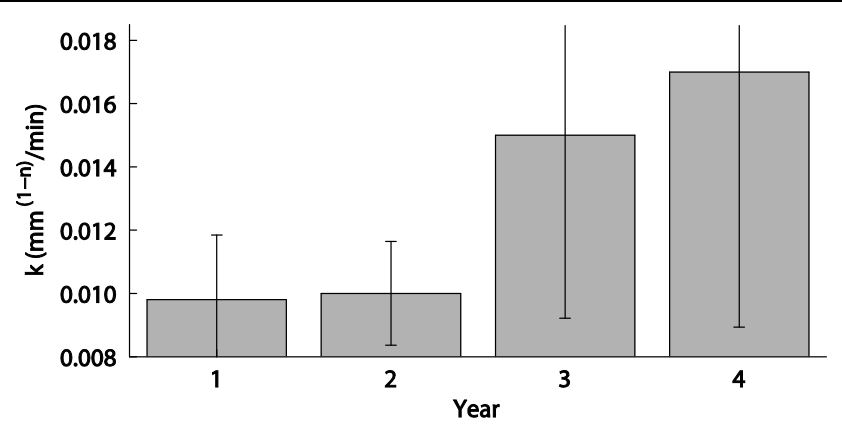

Figure 2. Yearly Mean Value of k.

Table 1. Detention Parameters of Design Storm for Observed k.

\begin{tabular}{llcc}
\hline \multirow{2}{*}{ Detention Parameter } & \multirow{2}{*}{ Units } & \multicolumn{2}{c}{$k\left(\mathrm{~mm}^{(1-\mathrm{n})} / \mathrm{min}\right)$} \\
\cline { 3 - 4 } & & 0.0098 & 0.0170 \\
\hline Peak Runoff & $\mathrm{mm} / \mathrm{min}$ & 3.47 & 4.19 \\
Peak Attenuation & $\%$ & 35.0 & 21.6 \\
Peak Delay & $\mathrm{min}$ & 2 & 2 \\
Centroid Delay & $\mathrm{min}$ & 15.6 & 10.9 \\
\hline
\end{tabular}

that have led to an increase in the value of $k$ are unknown. The number of processes occurring within the substrate make the exact cause difficult to determine. However it has been shown that the combined effects of these processes can be described through the $k$ value of a generic green roof model.

\section{REFERENCES}

1. Kasmin H, Stovin VR, Hathway E a. Towards a Generic RainfallRunoff Model for Green Roofs. Water Science \& Technology 2010;62:898-905.

2. Stovin V, Poë S, Berretta C. A Modelling Study of Long Term Green Roof Retention Performance. Journal of Environmental Management 2013;131:206-15.

3. Vesuviano GM. A Two-Stage Runoff Detention Model for a Green Roof. University of Sheffield, 2014.

4. Yio MHN, Stovin V, Werdin J, Vesuviano G. Experimental Analysis of Green Roof Substrate Detention Characteristics. Water Science and Technology: A Journal of the International Association on Water Pollution Research 2013;68:1477-86.

5. Getter KL, Rowe DB, Andresen J a. Quantifying the Effect of Slope on Extensive green Roof Stormwater Retention. Ecological Engineering 2007;31:225-31.

6. Schrader S, Böning M. Soil Formation on Green Roofs and its Contribution to Urban Biodiversity with Emphasis on Collembolans. Pedobiologia 2006;50:347-56.

7. Emilsson T, Rolf K. Comparison of Establishment Methods for Extensive Green Roofs in Southern Sweden. Urban Forestry \& Urban Greening 2005;3:103-11.

8. Nagase A, Dunnett N. The Relationship Between Percentage of Organic Matter in Substrate and Plant Growth in Extensive Green Roofs. Landscape and Urban Planning 2011;103:230-6.

9. Beattie D, Berghage R. Understanding the Importance of Growing Media Green Roof Media Characteristics : The Basics. 2nd North American Green Roof Conference: Greening Rooftops for Sustainable Communities, Portland, OR: The Cardinal Group; 2004. 